\title{
Territorios, inseguridad y autodefensas comunitarias en localidades de la Meseta Purépecha de Michoacán, México
}

GUILLERMO PALETA PÉREZ

> Unidad Académica de Estudios Regionales, UNAM Sede Jiquilpan, Michoacán, México. gpaleta@humanidades.unam.mx ANTONIO FUENTES DÍAZ

> Instituto de Ciencias Sociales y Humanidades de la Universidad Autónoma de Puebla, México. anfudi@gmail.com

Universidad de Valparaíso

Facultad de Arquitectura

Revista Márgenes

Espacio Arte Sociedad

Territorios, inseguridad y autodefensas comunitarias en localidades de la

Meseta Purépecha de Michoacán, México

Diciembre 2013 Vol. 10 No 13

Páginas 62 a 68

ISSN elec. 0719-4463

ISSN imp. 0718-4034

Recepción: Agosto 2013

Aceptación: Diciembre 2013

RESUMEN

El artículo trata de identificar procesos y contextos generales para entender la emergencia de los grupos de autodefensa comunitaria en la Región Meseta Purépecha en Michoacán, México durante el año 2013, a partir de la defensa del territorio y contra la inseguridad provocada por la presencia de grupos delictivos del crimen organizado. El artículo da contexto de las transformaciones socioeconómicas en la región y las respuestas que algunas comunidades han sostenido ante los embates macro-estructurales y delictivos.

PALABRAS CLAVE

autodefensa, territorio, seguridad, policía comunitaria, Michoacán

Territories, insecurity and community self-defence in localities of the

Purépecha plateau of Michoacán, Mexico

ABSTRACT

The article tries to identify processes and general context for understanding the emergence of community selfdefense groups in the region Meseta Purepecha in Michoacan, Mexico in 2013, from the defense of territory and against insecurity caused by the presence of criminal groups organized crime. The article gives context of socio-economic change in the region and the responses that some communities have argued against the macro-structural shocks and criminal.

KEYWORDS

self-defense, territory, safety, community police, Michoacan

Territoires, insécurité et autodéfense communautaire dans les localités

du plateau Purépecha de Michoacán, Mexique

RÉSUMÉ

L'article tente d'identifier les processus et les contextes généraux pour comprendre l'émergence de groupes communautaires d'autodéfense dans la région du plateau Purépecha de Michoacán, Mexique au cours de l'année 2013, à partir de la défense du territoire et contre l'insécurité causée par la présence de groupes associés au crime organisé. L'article présente le contexte des transformations socio-économiques dans la région et les réponses que certaines collectivités ont levé contre les avancées des macrostructures et des criminelles. MOTS CLÉS

autodéfense, territoire, sécurité, police de proximité, Michoacán

62 > Revista Márgenes No 13 Vol. 10 > Diciembre 2013: 62-68 


\section{INTRODUCCIÓN}

En la actualidad algunas regiones de México experimentan complejas problemáticas en el marco de procesos productivos globales y culturales a escala mundial. Algunos de los problemas a los que se enfrentan son la desigualdad social, la pobreza, crecimiento desordenado, flexibilidad en el mercado laboral, devastación de los recursos naturales, violencia y narcotráfico. La vivencia cotidiana de estas condiciones se exhibe y toma forma en el espacio social y geográfico.

A principios de 2011 y hacia los primeros meses de 2013, en las regiones occidente y suroeste de México, particularmente en los estados de Michoacán y Guerrero emergieron, en diferentes comunidades rurales, grupos organizados para la defensa comunitaria en contra del crimen organizado. Estos eventos no eran aislados ni recientes pues 17 años atrás en la Sierra y Costa Chica de Guerrero, se había conformado una red de seguridad para las comunidades de esa región, situación que había desembocado en la creación de una "policía comunitaria"1.

Para el caso de Michoacán los grupos de defensa comunitaria actuales argumentaban la presencia de rondas comunitarias en la región, por lo menos 40 años atrás e incluso aseveraban que su origen se remontaba al periodo denominado como "República de Indios"2. El fenómeno de auto-protección comunitaria, visibilizado en los primeros meses de 2013 , ganó notoriedad en cuanto a la aparente reacción en cadena en la creación de estos grupos, que en apenas 6 meses, de acuerdo a los reportes de medios de comunicación nacionales, fue de al menos 24 cuerpos de vigilancia comunitaria en estos dos estados y de 36 en el resto del país ${ }^{3}$.

La organización para la defensa comunitaria ha implicado procesos de construcción de mediano y largo plazo, en el que se destaca el aprendizaje de otras experiencias exitosas en cuanto a la contención y disminución de agravios a bienes y personas, que habían sido los detonantes para su conformación. Una de las experiencias con más arraigo y con mayores recursos comunitarios para el sostenimiento de sus cuerpos de seguridad, ha sido el caso de la Coordinadora Regional de Autoridades Comunitarias-Policía Comunitaria (CRAC-PC) de los pueblos de la Región de la Montaña y Costa Chica de Guerrero, fundada como tal en 1995, conformada dentro de un sistema integral de Justicia comunitaria fincada en la práctica del derecho consuetudinario.

En este artículo exploraremos dos experiencia de organización para la defensa comunitaria: la ronda comunitaria del municipio de Cherán, Michoacán, conformada en 2011 y la guardia comunitaria, creada recientemente, en julio de 2013 en la localidad de Cherato en el municipio de Los Reyes, también en Michoacán ${ }^{4}$. De esta manera, el objetivo de este artículo es identificar algunos procesos y contextos generales que nos permitan vislumbrar la emergencia de grupos de autodefensa comunitaria en la Región Meseta Purépecha en Michoacán, particularmente en las localidades de Cherán (cabecera municipal), y Cherato (tenencia del municipio de Los Reyes). Nuestro interés se centrará en el análisis respecto del argumento de defensa del bosque, para el caso de Cherán, y por la seguridad comunitaria en el caso de Cherato. Cabe mencionaar que en ambos casos se encuentra presente el argumento por la defensa del territorio y por la preservación de la seguridad comunitaria.

\section{EL ESTADO DE MICHOACÁN}

El estado de Michoacán de Ocampo tiene una población de 4.351.037 habitantes que lo ubican en el noveno lugar en el país por importancia poblacional. La entidad federativa tiene significativa diversidad étnica que se refleja en que 136.608 personas (entre 5 años de edad y más) hablan una lengua indígena (INEGI, 2010).

El promedio de escolaridad es de 7,4 años (primer grado de educación secundaria) que la posiciona como la cuarta entidad más baja en el país junto con Chiapas, Oaxaca y Guerrero (INEGI, 2010) Respecto a la oferta cultural podemos señalar que Michoacán cuenta con 1,0 a 1,2 espacios culturales ${ }^{6}$ por cada diez mil habitantes. El estado se ubica en la segunda escala más baja de medición, de cinco, en el registro de estos espacios en el país (Serra Puche y Salas, 2009).

El estado destaca en la producción ganadera, pesca, minería, agricultura y en servicios. La relevancia de la agricultura se debe a la diversidad ecológica, a sus climas, a sus cuencas hidrológicas, a la diversidad de suelos y a su mano de obra. La agricultura se lleva a cabo en poco más de un millón de hectáreas, cerca de 400.000 son de riego y 600.000 de temporal. El estado se ha posicionado en México y a nivel mundial en la producción de aguacate ${ }^{7}$, limón, guayaba, fresa, melón y zarzamora. En el 2010 la superficie cosechada en Michoacán ascendía al $72 \%$ de cereales y forrajes, el $23 \%$ frutas y hortalizas, el $5 \%$ de cultivos industriales, leguminosas y otros (SAGARPA, 2010). La importancia de la agricultura a nivel regional radica en que es una fuente de empleo para miles de trabajadores rurales ${ }^{8}$.

Michoacán no está exento de las principales problemáticas que aquejan al país. De la población total de Michoacán el 3\% tiene muy alto grado de marginación ${ }^{9}$, el $4 \%$ alto, el $45 \%$ medio, el $18 \%$ bajo y el $30 \%$ muy bajo, estos porcentajes lo ubican en el octavo estado con mayor índice de marginación (CONAPO, 2010). La marginación, la pobreza, la exclusión social, el deterioro de la tierra cultivable, las condiciones climáticas y las formas de vida regionales han coadyuvado a que el estado tenga históricamente experiencia migratoria internacional. En situación migratoria Michoacán, junto con otros estados del occidente de México ha sido históricamente, desde hace por lo menos cien años, expulsor de población a los Estados Unidos (Ochoa, 2003; Constantino, 2007). El estado se posiciona actualmente en el tercer lugar a nivel nacional ${ }^{10}$. Michoacán está considerado con el estatus de "Muy Alto" grado de migración.

Actualmente el estado de Michoacán experimenta alarmante deterioro ambiental, falta de infraestructura, malos servicios públicos, aumento exponencial de violencia por narcotráfico ${ }^{11}$, ilegalidad en sus territorios rurales ${ }^{12}$, incremento de la pobreza en el estado, altos niveles de migración internacional, bajos niveles educativos, deficiente oferta cultural, incremento de actividades económicas informales y escasa cobertura de seguridad social. Como consecuencia de esta complejidad de situaciones el estado enfrenta dificultades para mantener la sustentabilidad de los recursos naturales y para generar desarrollo en sus regiones y municipios.

Administrativamente el estado de Michoacán se encuentra dividido en 113 municipios y diez regiones geográficas. La definición regional del estado se sustenta en cuatro criterios básicos: cuenca hidrográfica, características físico-geográficas, socio-económicas y socioculturales. En términos administrativos el estado de Michoacán se encuentra organizado en diez regiones: 1. Lerma-Chapala; 2. Bajío 
Michoacano; 3. Cuitzeo; 4. Oriente; 5. Tepalcatepec; 6. Purépecha; 7. Pátzcuaro-Zirahúen; 8. Tierra Caliente; 9. Sierra-Costa; 10. Infiernillo. La organización del territorio michoacano por regiones responde al Plan Estatal de Desarrollo (2003-2008) planteado por la Secretaría de Planeación y Desarrollo (SEPLADE). La organización territorial toma en cuenta la vocación productiva de los municipios, índices de pobreza, marginación y deterioro ecológico.

\section{EL MOVIMIENTO INDÍGENA EN MICHOACÁN}

El movimiento comunitario organizado, los referentes discursivos, las alusiones de defensa del bosque y de la pertenencia étnica en Cherán, en particular, y en la Meseta Purépecha, en general, debe enmarcarse en coyunturas y acontecimientos mayores, fundamentalmente en la experiencia del movimiento indígena en Michoacán iniciado a finales de los años setenta del siglo XX. La organización que aglutinó diversas demandas fue la Unión de Comuneros Emiliano Zapata (UCEZ) que surgió en noviembre de 1979 en la comunidad de Tingambato. La lucha de esta comunidad se inició con demandas agrarias y concluyó con reivindicaciones étnicas a la par de la configuración de símbolos como la bandera y el lema purépecha que han sido utilizados para legitimar la lucha y convertirse en referentes para las comunidades purépechas (Jasso, 2010:66).
En 1981 se realizó el $2^{\circ}$ Encuentro de Organizaciones Indígenas Independientes de México, Centroamérica y el Caribe, en Cheranástico, Michoacán. Diez años después, en 1991 en Cherán se realizó el Primer Encuentro de Comunidades Indígenas de Michoacán. Del mismo modo, se constituyó el Frente Independiente de Comunidades Indígenas de Michoacán (FICIM) y el Frente Independiente de Pueblos Indios (FIPI-Michoacán). De acuerdo con Jasso (2010) con este acto se inició una etapa de organización y lucha por los intereses de las comunidades y se percibía una clara adscripción indígena. En este mismo año surge la Organización Nación Purépecha (ONP), movimiento indígena que planteó la defensa de la propiedad comunal. La ONP junto con otros grupos de indígenas purépechas declararon propiedad comunal todos los territorios que en forma ancestral [habian] venido utilizando las comunidades del pueblo purépecha (Jasso, 2010,:69). Del mismo modo Jasso (2010), argumenta que esta orientación de la ONP se acompaña de una visión ambientalista de conservación y protección de los recursos naturales, asimismo, se presenta una relación armónica entre indígenas y naturaleza, esta última visión se enmarca en contextos internacionales en donde se puede acceder a diversos recursos.

> Mapa 1. Meseta Purépecha, Michoacán, México, Fuente: INEGI, 2010. Conjunto de Datos Vectoriales. Elaboración: Celia López Miguel

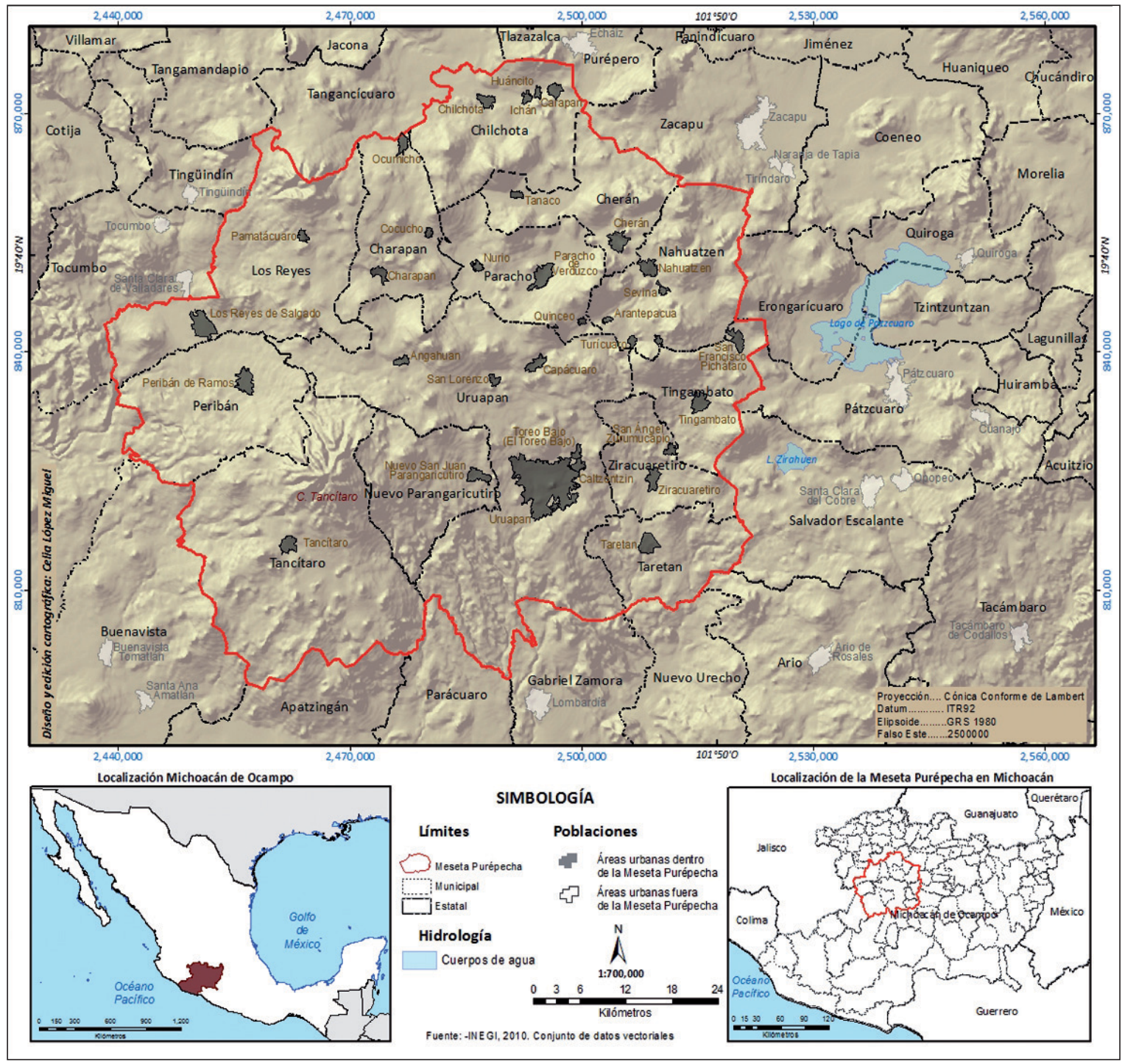

64 > Revista Márgenes N 13 Vol. 10 > Diciembre 2013: 62-68 
Para 1998 se crea la organización Nación Purépecha Zapatista (NPZ) con orientación cercana a los preceptos del Ejército Zapatista de Liberación Nacional (EZLN), surgido a la luz pública en 1994. La creación del NPZ obedece a las diferencias de lucha y de la distribución de los recursos de la ONP. La NPZ sustenta sus demandas en los artículos del 13 al 19 del Convenio 169 de la OIT para apoyar su derecho al reconocimiento de su territorio (Jasso, 2010). Así, a grandes rasgos estos serían algunos de los procesos del movimiento indígena en Michoacán que en buena medida han sido definitorios en las maneras de hacer política regional en algunas de las comunidades purépechas.

\section{LA MESETA PURÉPECHA}

La Región Meseta Purépecha se ubica al centro norte de Michoacán y está formada por 13 municipios: Charapan, Cherán, Chilchota, Nahuatzen, Nuevo Parangaricutiro, Paracho, Periban, Los Reyes, Tancitaro, Taretan, Tingambato, Uruapan y Ziracuaretiro. La región se caracteriza por sus extensos bosques templados, por la significativa presencia de población indígena, por sus elevados índices de pobreza, marginación y por su desigual acceso al agua para el consumo humano y para la producción agrícola. Los 13 municipios de la Meseta tienen un total de población de 624.257 habitantes (INEGI, 2010). Aquí se encuentra Uruapan, la ciudad regional más importante con 315.350 habitantes, esta ciudad articula y concentra en buena medida el comercio de la Meseta Purépecha.

\section{RONDA COMUNITARIA EN CHERÁN ${ }^{13}$}

El 15 de abril de 2011 comuneros del municipio de Cherán, Michoacán, perteneciente a la región Meseta Purépecha, se organizaron para la defensa de su territorio frente a la tala clandestina realizada por grupos identificados como parte del crimen organizado. El movimiento tomó fuerza porque apareció inicialmente frente a la opinión pública como un movimiento legítimo en defensa de su bosque. La población había padecido del asolo de grupos del narcotráfico conocidos como La Familia y los Caballeros Templarios, quienes a través del cohecho de las autoridades municipales, establecían controles territoriales con impunidad en su actuar. Parte de la ventaja de ese vínculo implicaba el uso indebido de bienes comunales como el bosque y el agua, así como la extorsión a los comerciantes de la región.

La reacción en contra del saqueo del bosque comunal, los secuestros, extorsiones y demás afrentas a los habitantes de Cherán, detonó un movimiento de autoprotección liderado por las mujeres que después de unos meses derivó en la conformación de una estructura permanente de seguridad y vigilancia en contra de las acciones represivas de los talamontes y demás grupos de crimen organizado. Al mantener la sospecha de que la Policía Ministerial estaba coludida en diversos actos ilícitos en la zona, en el pleno de una reunión comunitaria se determinó expulsarlos en agosto del mismo año.

En un primer momento, el detonante de la alerta, fue la defensa de los árboles que bordeaban un manantial denominado La Cofradía, en tanto que los talamontes clandestinos empezaron a talar árboles en esa zona conocida como El Calvario, de importancia estratégica para la comunidad dado que constituye un acuífero de importancia vital que por mucho tiempo fue la única fuente de abastecimiento de agua a la comunidad, así como un lugar central en la reproducción social comunitaria por encontrarse un santuario religioso que lleva el mismo nombre.
La población levantada enfrentó y expulsó a los talamontes armados y se organizó, ante el temor de represalias, en guardias de vecinos por cuadras a las que denominaron "fogatas", dado que se encendieron piras con el fin de aglutinar a los vecinos y pernoctar, realizando turnos de vigilancia por cada 12 horas. Cerraron los accesos de entrada al pueblo y utilizaron un sistema de alerta por cohetes para avisar sobre alguna eventualidad. Se constituyeron cerca de 200 "fogatas" en todo el pueblo.

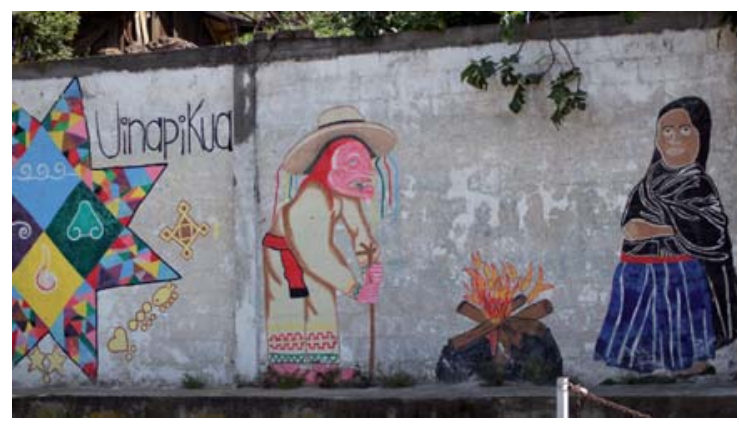

Figura 1. Grafiti que ilustra la participación de las mujeres en Cherán, en la instalación de fogatas junto con otros símbolos purépechas. Fuente: Autores.

Con la finalidad de darle permanencia a esas acciones de defensa y seguridad crearon dos cuerpos de seguridad diferenciados, una Policía o Ronda comunitaria, encargada de la seguridad civil y el patrullaje en los cuatro barrios de la comunidad ${ }^{14}$, y un cuerpo de guardabosques para la vigilancia de los montes comunales. Es importante señalar que ambos cuerpos se encuentran articulados a otras estructuras de mando y representación en la comunidad. La corrupción e indiferencia de las autoridades estatales y municipales ante las demandas de seguridad, hicieron que Cherán, a partir de la defensa de su territorio y su integridad comunitaria, transitara a la conformación de un gobierno autónomo de los partidos políticos y de los sistemas de representación oficiales. De esta manera, se creó una Estructura Orgánica de Gobierno Comunal para el periodo de 2012 a 2015.

Como máxima autoridad se encuentra la Gran Asamblea de la Comunidad (K`ERI TANGURHIKUA), en línea directa se encuentra el Consejo Mayor de Gobierno y los Cuatro Barrios. Existe en el organigrama del gobierno autónomo un Consejo Operativo Principal y la Tesorería. Del Consejo Mayor se desprende el Consejo de Administración Local, Consejo de Asuntos Civiles, Consejo de Programas Sociales, Consejo de Barrios, Consejo de Bienes Comunales, y Consejo de Procuración y Vigilancia; a este último se supedita la actuación de los cuerpos de policia comunitaria y guardabosques.

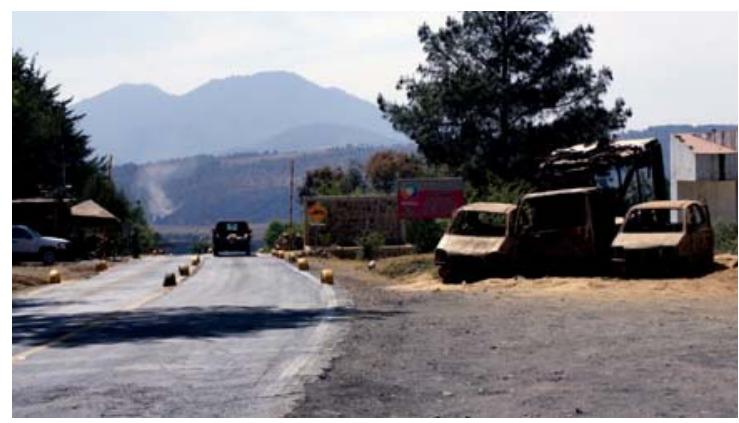

Figura 2. Puesto de control de la Policía Comunitaria en la carretera que comunica a Cherán. Fuente: Autores. 


\section{RONDAS COMUNITARIAS EN LOS REYES}

El municipio de Los Reyes se encuentra situado en la parte noroccidental del estado de Michoacán. Limita al norte con Tingüindin, al oeste con Tocumbo, al este con Charapan y Uruapan, al sur con Periban y el estado de Jalisco. La geografía municipal comprende tres zonas: el Valle, la Sierra y una pequeña parte del suroeste del municipio con características de la región llamada Tierra Caliente ${ }^{15}$. En 2009 el municipio de Los Reyes contaba con 64.164 habitantes localizados en 35 comunidades rurales (INEGI, 2010). En este mismo año mantenía población indígena purépecha en 19 comunidades, principalmente en la zona de Sierra ${ }^{16}$. Las diferencias entre estas tres zonas son evidentes y contrastantes, mientras que en el valle se concentran las actividades económicas y comerciales en las otras la precariedad y la falta de infraestructura es lo que impera.

En años recientes la economía de Los Reyes se sustentaba en la producción de azúcar mediante el funcionamiento de dos ingenios azucareros: San Sebastián y Santa Clara. Empero con la crisis azucarera experimentada a nivel mundial y con consecuencias graves para México es que a finales de los años noventa del siglo pasado el ingenio de San Sebastián se cierra con el propósito de que Santa Clara procesara toda la caña del valle ahorrándose los gastos de operación del primero. Esta situación aceleró de manera evidente el proceso de reconversión productiva de la región al buscarse nuevos cultivos alternos a la caña de azúcar. Así, se inicia el cultivo de berries ${ }^{17}$ en la zona. La importancia del cultivo de las frutillas ha sido tan relevante que en pocos años el municipio de Los Reyes se ha posicionado como el mayor productor de zarzamora en el mundo. A pesar del creciente número de hectáreas cultivadas de berries, aproximadamente 4 mil, aún hay una mayor cantidad de extensión cultivada de caña de azúcar, alrededor de 5 mil hectáreas. Es evidente la coexistencia de los dos principales productos cultivados en la zona (caña de azúcar y frutillas) junto con otros como el del aguacate ${ }^{18}$.

Al mismo tiempo que aparecían nuevos cultivos también se presentaban en el valle diferencias entre los nuevos productores por el uso del espacio agrícola. La importancia de los cultivos de frutillas y aguacate radica en que han sido las principales fuentes de empleo para los habitantes del valle y la zona serrana. Al ser una región donde la actividad comercial y la agricultura de exportación son relevantes, también existe una presencia, a decir de los pobladores, del crimen organizado, en particular la presencia del grupo delictivo denominado como los Caballeros Templarios.

Así, las localidades de Cherato, Cheratillo, 18 de Marzo y Oruscato empezaron a experimentar la presencia del crimen organizado al ser objeto del cobro de cuotas de extorsión, de 2.000 pesos (153 dólares) por cada hectárea de aguacate para los productores, y de 3 pesos ( 0.23 dólares) por kilogramo para los vendedores a pequeña escala. Se estima que el monto de las extorsiones para el año 2012 fue de 2.460 millones de pesos (189 millones de dólares) (Macias V. y Rosales R., 2013). Las comunidades solicitaron seguridad al municipio de Los Reyes para detener las extorsiones pero no obtuvieron respuesta alguna. Estas cuatro comunidades se encuentran entre los límites del valle y la zona serrana. Esta región se ha caracterizado por conflictos entre las diferentes comunidades que la conforman, uno de los más acentuados se da con Pamatácuaro y Zicuicho, principales localidades de la zona serrana, quienes desde hace años han pretendido separarse de Los Reyes y constituirse como nuevos municipios autónomos ${ }^{19}$.
Un problema adicional que enfrentan estas comunidades es la falta de agua para consumo humano. La petición de una perforación de un pozo profundo para abastecer de agua a las comunidades es añeja. Del mismo modo, existen peticiones para crear una clínica de salud y una escuela secundaria. La falta de infraestructura en esta zona es evidente, aunque en contraste, es posible observar algunas huertas de aguacate que sí disponen de agua para su cultivo. Es decir, que se privilegia el agua para el cultivo y no para el consumo humano en las comunidades.

En marzo de 2013 los grupos delincuenciales secuestraron al encargado del orden de Cherato como represalia por no acceder al pago de las extorsiones. Esta situación detonaría la formación de la Ronda Comunitaria en estas cuatro localidades para defenderse de la presencia del crimen organizado y al mismo tiempo para continuar con las demandas comunitarias de infraestructura y servicios. Una de las primeras acciones que realizaron ya como Ronda Comunitaria, fue el cierre de la carretera que conecta el valle con la sierra, se instalaron puestos de control que permitían vigilar los accesos a las comunidades. Dicha acción sin embargo, afectaba la libre circulación de los habitantes de las comunidades vecinas, que en algunos casos ven con cierta desconfianza la organización de Cherato.

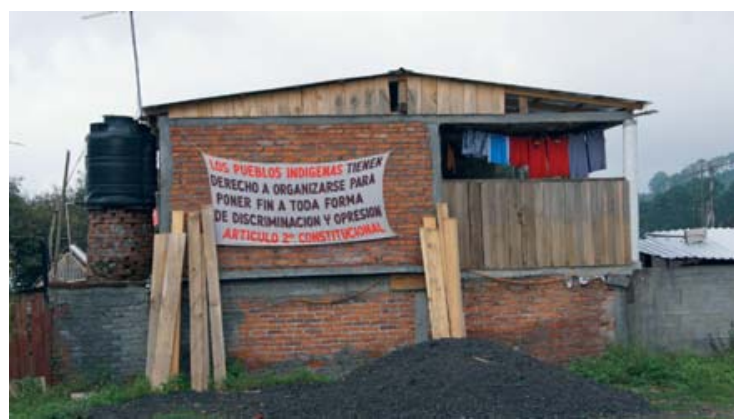

Figura 3. Espacio comunal donde se aloja la Ronda Comunitaria de Cherato. Fuente: Autores.

El 22 de julio de 2013 apareció como noticia nacional en México, el asesinato de cinco miembros de la guardia comunitaria de Los Reyes, Michoacán, mientras se manifestaban frente a la alcaldía del mismo municipio. Los aproximadamente 200 manifestantes exigían un alto al cobro extorsiones del grupo delictivo conocido como los Caballeros Templarios ${ }^{20}$, mientras fueron abatidos.

El 15 de septiembre de 2013 se realizó la toma de protesta de la Ronda Comunitaria en la localidad de Cherato, denominándose como "Comunidades Unidas: Cherato, Cheratillo, 18 de Marzo y Oruscato", en dicho evento se contó con la presencia de Guardias Comunitarias de Guerrero y Aquila, Michoacán y un miembro del Consejo Mayor de Cherán.

\section{CONCLUSIONES}

Comprender los entramados de estas dos experiencias de defensa comunitaria en la Meseta Purépecha de Michoacán tiene que pasar por el rastreo de sus particulares históricas y contextuales en los ámbitos regional y nacional, así como entender su vertebración con las transformaciones macro-sociales globales contemporáneas. Retomar los "focos rojos" 21 donde el $64,5 \%$ de las comunidades de la Meseta tienen algún tipo de conflicto por límites territoriales, que se traduce en que 16 mil 848 hectáreas asciende a la extensión en disputa ${ }^{22}$. Algunos de estos conflictos son de larga data (mayores a 40 años) (Ayala, 2006).
66 > Revista Márgenes № 13 Vol. 10 > Diciembre 2013: 62-68 Facultad de Arquitectura > Universidad de Valparaíso
$>$ ISSN electrónico 0719-4436
$>$ ISSN impreso 0718-4034 
El estudio del contexto de creación y funcionamiento de estas defensas comunitarias permite ser punto de comparación con otros colectivos organizados para la autoprotección presentes actualmente en otros escenarios de México y el mundo. Para el caso de la discusión que quieren plantearse aquí, dejaremos esa profundización para futuras investigaciones y debates. Sin embargo podemos mencionar ahora algunos:

- Entre los elementos detonantes que permiten entender la emergencia de la autodefensa comunitaria en la región podemos encontrar la sensación de agravio a los bienes comunales y privados de la población, traducidos en abusos, asesinatos, robos, y extorsiones ejercidos por diversos agentes: Estado y crimen organizado, ello dentro de un contexto de transformaciones macro sociales e ineficacia de las instituciones estatales de seguridad y justicia.

- En los últimos 30 años, la estructura económica de México se modificó notablemente, dicho cambio impactó la producción agrícola y el mundo rural campesino, muchas veces en términos desfavorables. La adecuación para el impulso a la nueva forma de la acumulación de capital comprendió una serie de eventos, entre ellos: cambio en el uso de suelo, reconversión productiva de productos agrícolas hacia cultivos industriales, uso ilegal e ilegítimo de bienes comunales con fines de extracción intensiva.

- En las comunidades de la Meseta Purépecha podemos notar algunas de estas transformaciones, como la expansión significativa de la producción de aguacate y zarzamora, que apoyada en el trabajo de jornaleros mal remunerados nos habla de un mercado dinámico con altos rendimientos económicos, mismo que fue atractivo para la diversificación de las actividades delictivas del crimen organizado.

- El crimen organizado, particularmente los grupos de narcotráfico, también fueron impactados por las transformaciones en los mercados ilegales de las drogas y otras actividades delictivas e informales en la región. Lo anterior y la nueva relación descentralizada en su regulación respecto del Estado mexicano a partir de los años 90 del siglo XX, hizo que tendieran a la diversificación de sus actividades delictivas para mantener sus elevadas tasas de ganancia por vías diferentes a la siembra y trasiego de sustancias ilegales hacia los Estados Unidos. En dicha diversificación toma cuerpo la extorsión, el secuestro, pero también la tala clandestina en bosques comunales.

- Los trastrocamientos estructurales en la economía, factores ambientales como la escasez de agua y los embates inducidos por los grupos delictivos, han generado sensaciones de vulnerabilidad en las poblaciones rurales en Michoacán, y una clara percepción de la ineficacia del Estado para proporcionar seguridad y justicia.

- La emergencia de los grupos de autodefensa, proviene de una experiencia diferenciada de la violencia, en algunos casos quienes se organizan por la "seguridad" no son los más pobres, como en el caso de los productores de aguacate y zarzamora en el muncipio de Los Reyes. En otros casos, como en Cherán, el núcleo de la participación ha sido más colectiva y perfila horizontes políticos más complejos en la organización.

Hace algunos años la demanda principal de las comunidades del municipio de Los Reyes era la de infraestructura (carreteras, dotación de agua, escuelas y clínicas de salud) hoy día solicitan "seguridad" al Estado, o la crean por sí mismos, ejerciendo la autodefensa como un derecho propio. Estas experiencias son complejas en sí mismas porque revelan aspiraciones de organización política de mayor proyección.
Observamos en términos generales, una tendencia a la instauración de órdenes de justicia y seguridad que rebasan la mediación estatal, a través de un tipo de autoafirmación comunitaria, que podría tender a la instauración de micro-soberanías en conflicto con el Estado. Sin duda, estamos en presencia de nuevos escenarios rurales, cuyo impacto en la configuración política regional y estatal será relevante en el futuro.

\section{BIBLIOGRAFÍA}

ARRIOJA L. A. (2008) Pueblos de indios, tierras y economía: Villa Alta (Oaxaca) en la transición de Colonia a República, 1742-1856. Tesis de doctorado en historia. El Colegio de México, 646 páginas. México.

AYALA C. A. (2006) La mediación como alternativa de solución de conflictos: el caso de los "focos rojos". En Revista Estudios Agrarios. Número 32. México.

CONAPO (2010) Índices de marginación por localidad. México.

INSTITUTO NACIONAL DE ESTADÍSTICA, GEOGRAFÍA E INFORMÁTICA INEGI (2010) XIII Censo General de Población y Vivienda. México.

JASSO MARTÍNEZ I. J. (2010) "Las demandas de las organizaciones purépechas y el movimiento indígena en Michoacán”. En Revista Liminar. Estudios Sociales y Humanísticos. Año 8, Volumen VIII, núm. I. San Cristóbal de las Casas, Chiapas, México.

MACIAS V. y ROSALES R. (2013) "Extorsión a aguacateros da a Templarios 2.000 millones de pesos al año". En El Economista, http://m.eleconomista/seguridadpublica, fecha de consulta 2/11/2013.

MALDONADO S. (2012) “Drogas, violencia y militarización en el México rural. El caso de Michoacán". Revista Mexicana de Sociología. Año 74. N 1. Enero-Marzo. IIS-UNAM. Páginas 5-39.

(2010) Los márgenes del Estado mexicano. Territorios ilegales, desarrollo y violencia en Michoacán. El Colegio de Michoacán A, C.

MALKIN V. (2001) “Narcotráfico, migración y modernidad”. En Zárate, Eduardo (coord.) La Tierra Caliente de Michoacán. El Colegio de Michoacán A, C, Gobierno del Estado de Michoacán.

PALETA G. (2012) "Territorios y ruralidades: Jornaleros agrícolas en el cultivo de zarzamora en el valle de Los Reyes, Michoacán, México". En Revista de Antropología Experimental. $\mathrm{N}^{\circ}$ 12. Universidad de Jaén, España. Páginas 17-28.

SECRETARIA DE PLANEACIÓN Y DESARROLLO ESTATAL (2004) Nueva regionalización para la planeación y Desarrollo del estado de Michoacán. Gobierno del Estado de Michoacán de Ocampo, México.

SERRA PUCHE M. C. y SALAS H. (2009) Información sobre la cultura en México. Coordinación de Planeación. Dirección General de Proyectos Universitarios, UNAM.

\section{NOTAS}

1 En este artículo se tomará indistintamente la nominación de policía comunitaria, guardia, autodefensa y ronda comunitaria, 
respetando las propias nominaciones de los grupos. A lo que aludimos con estos términos, por ahora indiferenciados, es a aquellos grupos o segmentos de comunidades organizados para la defensa y la seguridad de su comunidad o territorio. La distinción entre los términos no es clara aún en el debate político actual y pensamos que requiere de mayor precisión conceptual. Ese debate no se realizará en este artículo.

2 La república o el gobierno indígena se instauró desde el siglo XVI, casi al mismo tiempo en que la población nativa fue sometida y congregada por los primeros conquistadores. De hecho, desde 1549, se autorizó fijar en cada pueblo una corporación de tipo municipal en la que se podría implantar un cabildo de origen castellano. La institución se estableció en la inmensa mayoría de los pueblos y fue uno de los primeros pasos que dio la Corona para ejercer su control sobre la población nativa. [...] los caciques indígenas sirvieron como intermediarios del poder español, privilegiando más su función como oficiales de la Corona que como representantes del común de naturales (Arrioja, 2008:186-187).

3 “Las armas del pueblo". La Jornada del Campo. Número 68, 18 de mayo de 2013.

4 Existen otros grupos de auto-defensa en Michoacán, particularmente en las regiones conocidas como Tierra Caliente y en la Costa, sin embargo, por los intereses en este artículo solo abordaremos los casos de Cherán y Los Reyes.

5 El promedio nacional es de 8,6 años (segundo grado de secundaria). Las entidades con mayor escolaridad son: Distrito Federal $(10,5)$, Nuevo León $(9,8)$, Coahuila $(9,5)$ y Sonora $(9,4)($ INEGI, 2010).

6 Por espacios culturales se entiende toda la infraestructura creada por el Estado para difundir la creación cultural, así como para formar recursos humanos creadores o consumidores de servicios culturales. Esta categoría incluye, museos, teatros, centros culturales, galerías, auditorios, bibliotecas, librerías, centros de desarrollo indígena, casas de artesanía, universidades y centros de educación artística (Serra Puche y Salas H., 2009:41).

7 También conocido en Sudamérica como Palta.

8 Una parte significativa de estos trabajadores son jornaleros agrícolas. En el 2009 había aproximadamente 3,1 millones de jornaleros en el país y un poco más de 120 mil jornaleros en Michoacán (Paleta, 2012:18).

9 El índice de marginación considera cuatro dimensiones estructurales de la marginación; identifica nueve formas de exclusión y mide su intensidad espacial como porcentaje de la población que no participa del disfrute de bienes y servicios esenciales para el desarrollo de sus capacidades básicas. Es una medida-resumen que permite diferenciar entidades federativas y municipios según el impacto global de las carencias que padece la población, como resultado de la falta de acceso a la educación, la residencia en viviendas inadecuadas, la percepción de ingresos monetarios insuficientes y las relacionadas con la residencia en localidades pequeñas (CONAPO, 2010).

10 “Michoacán ocupa el tercer lugar a nivel nacional en migración, informa COESPO". La Jornada Michoacán. 24 de enero de 2012.

11 Existen excelentes ejemplos en Michoacán de la compleja relación

68 > Revista Márgenes № 13 Vol. 10 > Diciembre 2013: 62-68 Facultad de Arquitectura > Universidad de Valparaíso entre el desarrollo rural, los problemas de ciudadanía y violencia por narcotráfico (Cfr. Maldonado, 2012; Maldonado, 2010). También existen perspectivas que relacionan en la entidad la migración internacional con el narcotráfico (Cfr. Malkin, 2001).

12 Para Maldonado (2010:433) el narcotráfico es la expresión más evidente de cómo los territorios se transformaron por diversos procesos económicos, políticos y culturales en zonas ilegales.

13 Es uno de los 113 municipios que conforman el estado de Michoacán. Su población en el 2010 ascendía a 18.141 habitantes (INEGI, 2010). Limita con Ios municipios de Zacapu, Nahuatzen, Paracho y Chilchota.

14 Barrio primero (Jarhukutini), barrio segundo (Ketsikua), barrio tercero (Karakua) y barrio cuarto (Parhikutini).

15 Sitio web www.losreyesmichoacan.gob.mx Fecha de consulta 12 de enero de 2011.

16 Sitio web www.losreyesmichoacan.gob.mx Fecha de consulta 12 de enero de 2011.

17 Nombre genérico de las frutillas (zarzamora, fresa, arándano, frambuesa, mora, etcétera).

18 Palta. México es el mayor productor de aguacate del mundo y Michoacán el mayor productor en el país.

19 Al pretender ser nuevos municipios, en caso de lograrlo, asegurarían un presupuesto estatal e independencia de Los Reyes. Asimismo, la pretensión es convertirse en municipios indígenas autónomos y regirse por usos y costumbres.

20 "Michoacán: matan a 5 comunitarios durante protesta contra templarios". Semanario Proceso. 22 de julio de 2013. http:// www.proceso.com.mx/?p= 348083

21 Término utilizado por la Secretaría de la Reforma Agraria (SRA) para hacer referencia a los conflictos agrarios en México.

22 "Presentan problemas el 64,5\% de las comunidades de la Meseta Purépecha". http://www.marmorinforma.mx/Michoacan/ Estado/Presentan-problemas-el-64.5-de-las-comunidades-dela-Meseta-Purepecha 